\title{
Development of an Apparatus for Measuring the Load Acting on Joint Sealant when Movement Occurs
}

\author{
Saori Ishihara $^{1}$, Hiroyuki Miyauchi ${ }^{2}$, Akihiko Ito $^{3}$ and Kyoji Tanaka ${ }^{4}$ \\ ${ }^{1}$ Chiba Institute of Technology, 2-17-1 Tsudanuma Narashino-shi Chiba, Japan, \\ saori.ishihara@it-chiba.ac.jp \\ ${ }^{2}$ Building Research Institute, Ibaraki, Japan, miyauchi@kenken.go.jp \\ ${ }^{3}$ Auto Chemical Industry, Co., Ltd., Ibaraki, Japan, akihiko.ito@autochem.co.jp \\ ${ }^{4}$ Tokyo Institute of Technology, Yokohama, Japan, tanaka-kyoji@kme.biglobe.ne.jp
}

\begin{abstract}
The sealant that fills the joints of an exterior walls of building is subjected to weather loads, such as sunlight, ambient temperature, and rain, as well as a movement of the joints. As a result, the sealant gradually deteriorates under the combined deterioration factors of weathering and movement. Meanwhile, the results of a 15-year outdoor dynamic exposure test conducted in Japan using the methodology of ISO 11617 showed that the progress of damage varies greatly depending on the type of sealant and the stress relaxation rate. However, the mechanism of damage progression is unclear. In the present study, we focused on the load when the sealant moves and developed a load-measuring apparatus as the first step in clarifying the relationship between the progress of damage and the load. The load was measured at $-20,23$, and $40^{\circ} \mathrm{C}$ for test specimens with different stress relaxation rates, and it was confirmed that the developed load-measuring apparatus was able to measure the load correctly. Furthermore, it was shown that it is difficult for the stress of the sealant with a high stress relaxation rate to relax over time at low temperature but easy at high temperature, and the load increases when switching from the compressed state to the extended state.
\end{abstract}

Keywords: Joint Sealant, Load Measuring Apparatus, Joint Movement, Deterioration, Durability.

\section{Introduction}

The sealant used for a joint of an exterior wall is affected by various environmental factors, such as ultraviolet rays, the air temperature, and rain, and is gradually degraded by movement of the joint. In Japan, in the 15 years since 1992, dynamic outdoor exposure tests were carried out at three locations having warm, subtropical, and cold climates using a variable sealant as defined by ISO 2014: 11617. It was found that most sealants deteriorated remarkably at the subtropical location where irradiation by ultraviolet rays was strong. However, for some sealants (having a high stress relaxation rate), the damage depth (Df value) near the adherend was more remarkable at the warm and cold locations than at the subtropical location as shown in Fig. 1. It was believed that this was due to the load that the sealant received when movement occurred.

However, few studies have clarified the damage to sealants in terms of the load they are subjected to during service life. Further, commercially available accelerated testing machines are either accelerated weathering or fatigue testing machines, most studies have been limited to either of them. In the case of a material, such as a sealant, in which deterioration progresses due to the combined action of the weathering and the movement, it is desirable to verify the 
durability by an acceleration test in which the weathering and the movement are simultaneously loaded.

In this study, as a first step to explain the mechanism by which deterioration is more intense in cold regions, we aim to develop an apparatus that measures the load applied to a sealant when both the weathering and the movement are combined. We fabricated prototype sealant with different stress relaxation rates and verified whether the load acting on the prototype sealant can be measured properly with a load-measuring apparatus.

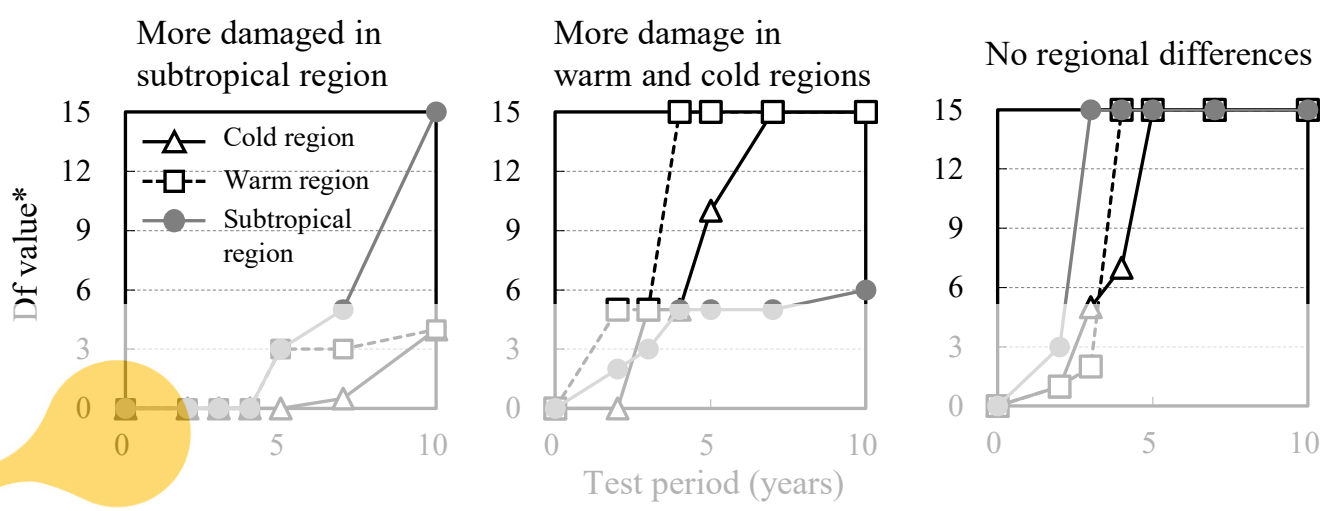

Figure 1. Example results of an outdoor dynamic exposure test.

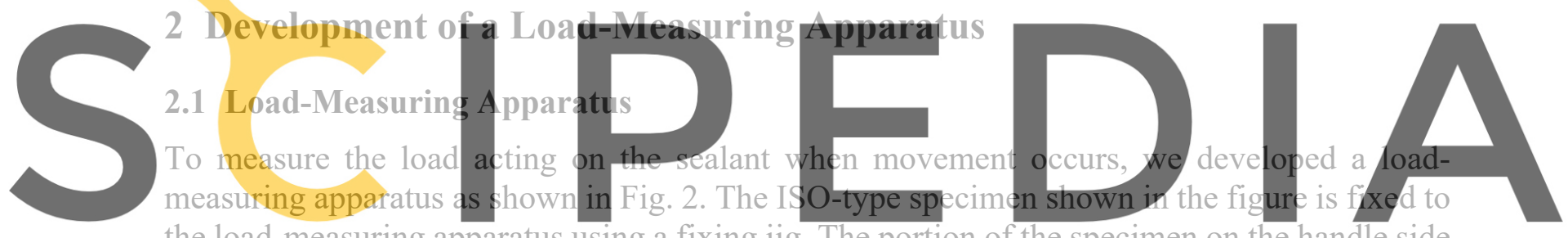

the load-measuring apparatus using a fixing jig. The portion of the specimen on the handle side

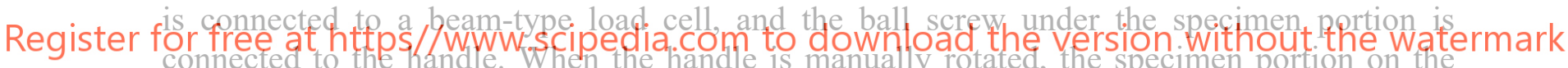

handle side moves horizontally, the sealant can be put into a compression or extension state,

and the load generated in the sealant at that time can be measured by the load cell. A guide prevents displacement in the shear direction being applied to the specimen itself when movement is applied to the specimen. The dynamic outdoor exposure tests described above were carried out under various temperature conditions, and the temperature around the specimen could change. However, because the load cell is highly sensitive to temperature, the load cell is installed slightly away from the specimen so as not to be affected by temperature.

\subsection{Prototype Sealant and its Stress Relaxation Ratio}

As described above, sealants with high stress relaxation rates in the dynamic outdoor exposure test degraded greatly in a cold region. Two prototype sealants with different stress relaxation rates were therefore fabricated for testing in the present study.

The prototype sealants were two-component modified silicone sealants with different mixing ratios of the base material and curing agent. The sealants were intended to have almost the same moduli after standard curing but different stress relaxation rates.

To confirm that the intended sealants could be produced experimentally, test specimens of the 


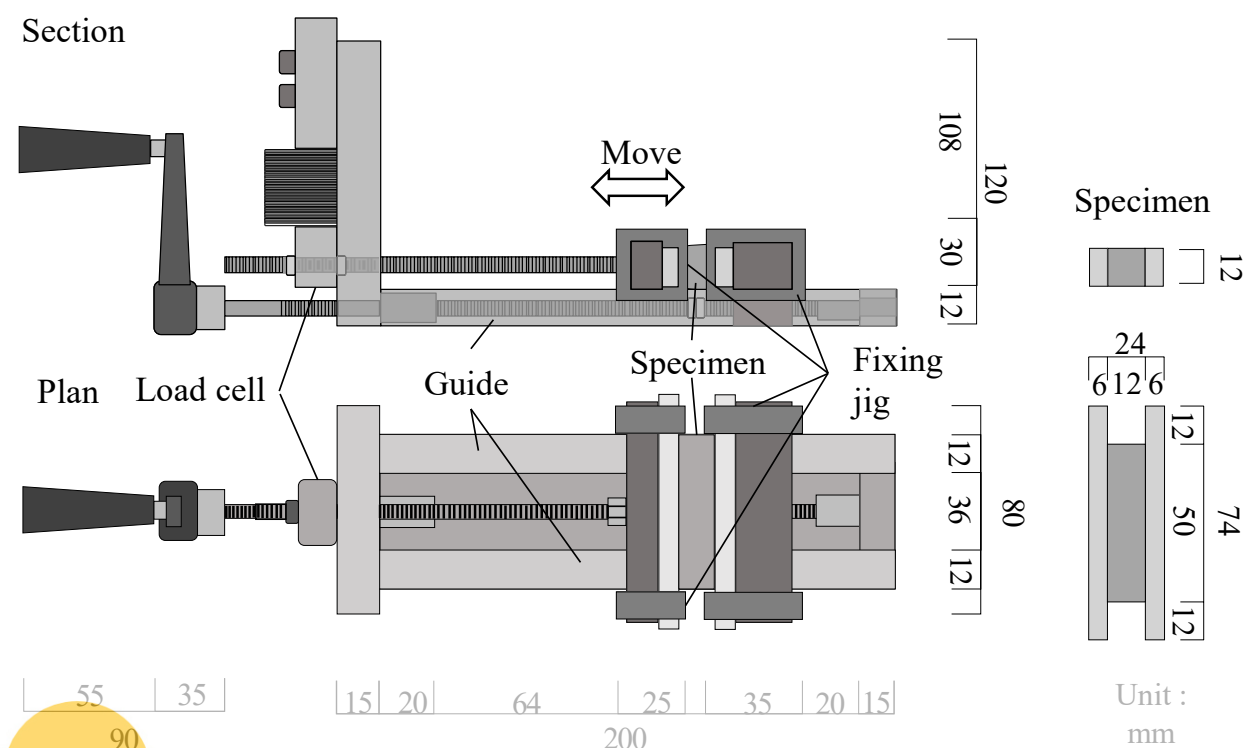

Figure 2. Load-measuring apparatus.

tensile adhesiveness test specified in JIS A 1439 were prepared using the prototype sealants (cured at $23{ }^{\circ} \mathrm{C}$ and $50 \%$ relative humidity for 7 days and at $50{ }^{\circ} \mathrm{C}$ and $50 \%$ relative humidity for 7 days, where the adherend was aluminum), and the stress relaxation rate was measured. Each specimen was attached to a tensite testing machine, the specimen width was extended by $30 \%$ (from 12 to $15.6 \mathrm{~mm}$ ), and the stres was measured when the specinen was hours in this state. The temperature was $23{ }^{\circ} \mathrm{C}$ and the tensile rate was $50 \mathrm{~mm} / \mathrm{min}$. The temporal variation of stress is shown in Fig. 3 while physical properties, including the stress relaxation rate, are given in Table 1. The stress was a maximum when the specimen was extended by $30 \%$ and it lowered immediately afterwards. The stress did tot decrease remarkably with time for specimen 1 having a low stress relaxation rate but lowered remarkably

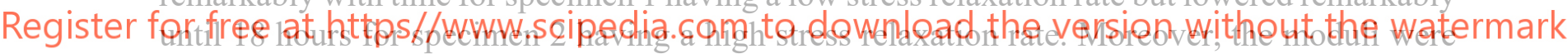
almost the same, and it can be said that the aim of creating prototype sealants with almost the same initial modulus but different stress relaxation rates was achieved.

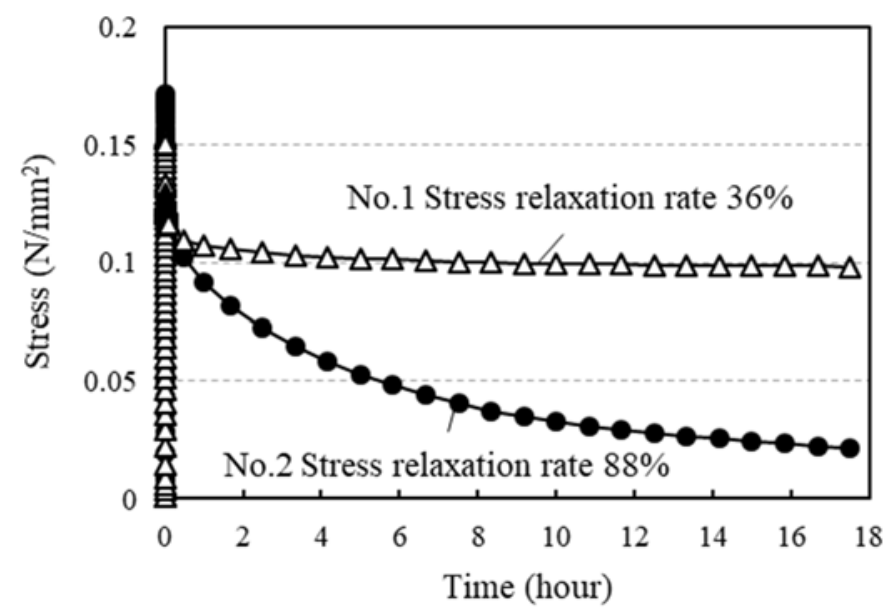

Figure 3. Temporal variation of stress. 
Saori Ishihara, Hiroyuki Miyauchi Akihiko Ito and Kyoji Tanaka

Table 1. Physical properties of prototype sealant after standard curing.

\begin{tabular}{c|c|c|c|c}
\hline \multirow{2}{*}{ Specimen } & \multirow{2}{*}{$\begin{array}{c}\text { Stress relaxation } \\
\text { rate }^{* 1}(\%)\end{array}$} & \multicolumn{3}{|c}{ Tensile adhesion $^{* 2}$} \\
\cline { 3 - 5 } & $\begin{array}{c}\mathrm{M}_{50} \\
\left(\mathrm{~N} / \mathrm{mm}^{2}\right)\end{array}$ & $\begin{array}{c}\text { Tmax } \\
\left(\mathrm{N} / \mathrm{mm}^{2}\right)\end{array}$ & $\begin{array}{c}\text { Emax } \\
(\%)\end{array}$ \\
\hline Specimen1 & 36 & 0.18 & 0.30 & 677 \\
\hline Specimen2 & 88 & 0.15 & 0.31 & 758 \\
\hline
\end{tabular}

$* 1$ : Stress relaxation rate $(\%)=($ Maximum stress - Stress after 18 hours $) \quad / \quad$ MaximumStress $\times 100$,

Tensile speed $50 \mathrm{~mm} / \mathrm{min}$, Temperature of $23^{\circ} \mathrm{C}$

*2: M 50: 50\% modulus, Tmax: ultimate tensile stress, Emax: elongation at Tmax

\subsection{Load-Measuring Procedure}

To determine whether the load can be measured properly with the load-measuring apparatus, the joint width was compressed by 30\% (from 12 to $8.4 \mathrm{~mm}$ ) and held for 24 hours, and then extended by $30 \%$ (from 12 to $15.6 \mathrm{~mm}$ ) and held for 24 hours, and the load was measured. The movement was realized manually as described above. The speed of movement was set to 50$100 \mathrm{~mm} / \mathrm{min}$ with some variation.

As described above, there was more remarkable damage at the warm location and cold location than at the subtropical location in the dynamic outdoor exposure tests, and the present experiment was thus conducted taking the ambient temperature around the test specimen as a variable. The temperatu temperature $\left(-20^{\circ} \mathrm{C}\right)$ temperature condition temperature condition temperature condition with a box lined with insulating material and a planar heating element.
In cases of low and high temperature, only the temperature around the specimen was adjusted

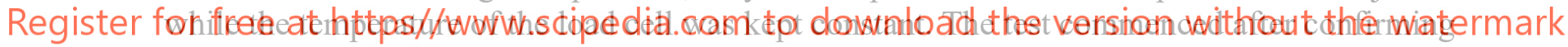
that the internal temperature of the specimen was similar to the ambient temperature.

\subsection{Test Results}

Test results are shown in Fig. 4. For both specimens, the load peaked immediately upon movement but rapidly decreased immediately after and continued to decrease gradually with time. The decrease was remarkable for specimen 2 having a stress relaxation rate of $88 \%$ at normal and high temperatures. In other words, when the stress relaxation rate was high, the effect of temperature was strong, and the maximum load when switching to extension was large especially at high temperature. Furthermore, there was cohesive fracture during switching to extension at high temperature, and fracturing continued to progress even during holding in extension. The stress after 24 hours of compression had greatly relaxed, and it is thus considered that the sealant adapted to the compression state and the change due to the load generated in the next extension became large.

Table 2 shows the stress relaxation rate for extension. The stress relaxation rate at normal temperature $\left(23^{\circ} \mathrm{C}\right)$ was slightly lower than that given in Table 1 , which was measured by a tensile testing machine, because the specimen was extended after the compression state was 
maintained. However, the difference in the stress relaxation rate was clearly well measured by Table 2 shows the stress relaxation rate for extension. The stress relaxation rate at normal temperature $\left(23^{\circ} \mathrm{C}\right)$ was slightly lower than that given in Table 1 , which was measured by a tensile testing machine, because the specimen was extended after the compression state was maintained. However, the difference in the stress relaxation rate was clearly well measured by the developed load-measuring apparatus, and it is considered that the change in stress with time can be appropriately measured even if the temperature of the environment changes.

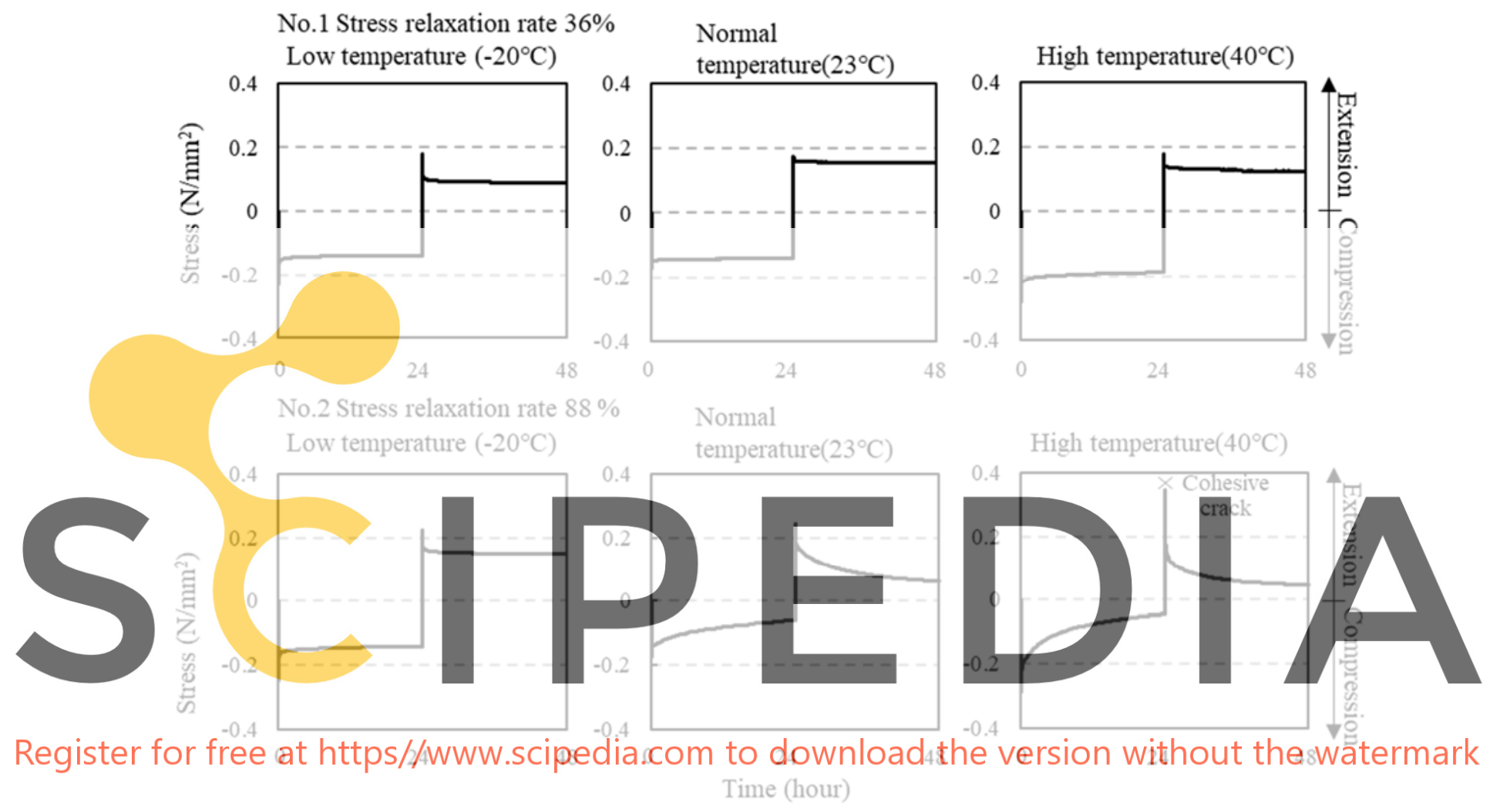

Figure 4. Temporal variation of stress.

Table 2. Stress relaxation rate measured by the load-measuring apparatus.

\begin{tabular}{c|c|c|c}
\hline \multirow{2}{*}{ Specimen } & \multicolumn{3}{|c}{ Stress relaxation rate in extension as measured by the load-measuring apparatus ${ }^{* 1}(\%)$} \\
\cline { 2 - 4 } & Low temperature $\left(-20^{\circ} \mathrm{C}\right)$ & Normal temperature $\left(23^{\circ} \mathrm{C}\right)$ & High temperature $\left(40^{\circ} \mathrm{C}\right)$ \\
\hline Specimen1 & 50 & 11 & 30 \\
\hline Specimen2 & 61 & 72 & 92 \\
\hline
\end{tabular}

\section{Conclusion}

The main contributions of the present study are as follows.

- We have developed an apparatus for measuring the load on a sealant during movement. Although an apparatus can handle any deformation rate, any temperature environment, any speed, and any movement period, it is difficult to perfectly match the movement speed each time because it is manually operated at present. Therefore, it is planned to 
develop a load-measuring device for automatically generating a movement in the future.

- In order to verify the validity of the apparatus, we measured the load when $30 \%$ deformation was given at temperature $\left(23^{\circ} \mathrm{C}\right)$, high temperature $\left(40^{\circ} \mathrm{C}\right)$, and low temperature $\left(-20^{\circ} \mathrm{C}\right)$ using two kinds of modified silicone sealants with different stress relaxation rates, it was found that the load gradually relaxed after compression and extension at normal temperature and high temperature but hardly relaxed at low temperature for prototype sealant with a stress relaxation rate of $88 \%$. Meanwhile, the prototype sealant with a stress relaxation rate of $36 \%$ was hardly affected by temperature. The effect of temperature on the load can be measured using the load-measuring apparatus. It was shown that the effect of temperature on the load can be measured using the load-measuring apparatus.

- Although the purpose of this study was to develop of a load-measuring apparatus, our ultimate goal is to clarify the occurrence of sealant damage from the viewpoint of the load applied to the sealant. Therefore, in the future, it is planned to carry out repeated load measurement while applying other weathering such as ultraviolet rays by changing the type of sealant, stress relaxation rate, and deformation.

\section{ORCID}

Saori Ishihara: http://orcid.org/ 0000-0002-4990-5519

References

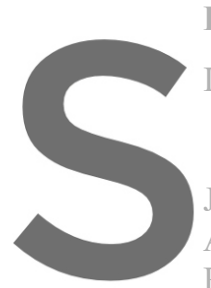

ISO $11617(2014)(\mathrm{E})$. and appearance of ela weathering and mechanic

JIS A 1439 (2004). Testi

ASTM STP 1453(2004)

Ramesh B. Malla, Matu R. S
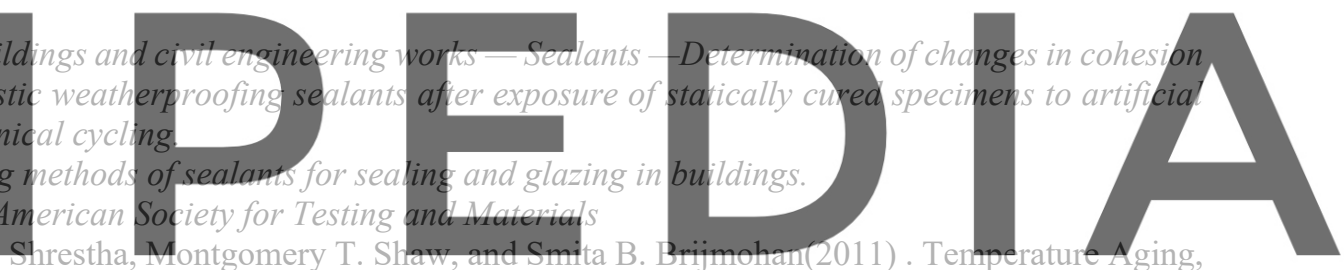

Compression Recovery, Creep, and Weathering of a Foam Silicone Sealant for Bridge Expansion Joints.

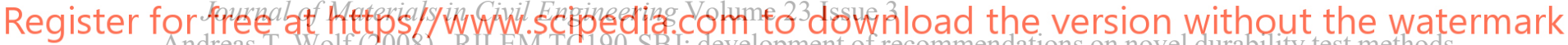

Andreas T. Wolf (2008). RILEM TC190-SBJ: development of recommendations on novel durability test methods for wet-applied curtain-wall sealants. Materials and Structures 41 , 1473-1486. doi: 10.1617/s11527-0089418-2

Noriyoshi Enomono and Kyoji Tanaka (2008). Quantification of Effect of Dynamic Movement for Weatherability of Construction Sealants. In Proceedings of the $11^{\text {th }}$ International Conference on Durability of Building Materials and Components.

Hiroyuki Miyauchi, Noriyoshi Enomoto, Shigeki Sugiyama, and Kyoji Tanaka (2004). Artificial weathering and cyclicmovement test results based on RILEM TC 139 - DBS durability test method forconstruction sealants. In Proceedings of the Symposium on Durability of Construction Sealants and Adhesives

Su Hua Ding and Da Zhuang Liu(2006). Durability evaluation of building sealants by accelerated weathering and thermal analysis Construction and Building Materials Volume 20, Issue 10, 878-881.

Noriyoshi Enomono, Akihiko Ito, and Kyoji Tanaka (2009). Quantification of Effect of Enforced Cyclic Movement and Regional Exposure Factors on Weatherability of Construction Sealants J. Struct. Constr. Eng., AIJ, 73(633), 1907-1912. doi: 10.1520/JAI101949

Christopher C. White, Donald L. Hunston, Kar Tean Tan, James J. Filliben, Adam L. Pintar,and Greg Schueneman (2012). A Systematic Approach to the Study of Accelerated Weathering of Building Joint Sealants Journal of ASTM International, Vol. 9, No. 5.

Barbora Nečasováa, Pavel Liškaa, and Jiří Šlanhof (2017). Adhesion and Cohesion Testing of Joint Sealants after Artificial Weathering - New Test Method Procedia Engineering 190, 140-147. 